\title{
Characteristics of primary biliary cirrhosis in British Columbia's First Nations population
}

\author{
Laura Arbour MD FRCPC FCCMG ${ }^{1}$, Rosemarie Rupps MSc ${ }^{1}$, Leigh Field PhD ${ }^{1}$, Paul Ross BSc ${ }^{2}$, Anders Erikson BSc ${ }^{3}$, \\ Harvey Henderson MD, Warren Hill PhD ${ }^{4}$, Eric M Yoshida MD MHSc FRCPC ${ }^{2,5}$
}

\begin{abstract}
L Arbour, R Rupps, L Field, et al. Characteristics of primary biliary cirrhosis in British Columbia's First Nations population. Can J Gastroenterol 2005;19(5):305-310.
\end{abstract}

Primary biliary cirrhosis $(\mathrm{PBC})$ is a rare, autoimmune liver disorder characterized by progressive destruction of intrahepatic bile ducts, that results in portal inflammation, scarring, cirrhosis and, eventually, liver failure. Although considered rare in Canadian populations, it is the leading indication for referral for liver transplantation in British Columbia's First Nations population. Previously, an expanded review of all cases referred to the British Columbia Transplant Society for PBC was carried out comparing the demographics of those of First Nations descent with those not of First Nations descent. The review suggested that the rate of referral for transplantation was eight times higher for those of First Nations descent compared with those of other descent $(\mathrm{P}=0.0001)$, and a disproportionate number of the First Nations cases lived on Vancouver Island (48\% of cases versus $18 \%$ expected, $\mathrm{P}<0.05$ ). Additionally, the age of referral was significantly younger ( 45.9 versus 54.3 years) for those of First Nations descent and there are fewer First Nations men referred $(1: 34)$ than expected. For the purpose of the present report, 28 symptomatic cases were ascertained separately and reviewed in a clinical study to delineate the features of this population. RESULTS: Although available liver biopsy reports were consistent with $\mathrm{PBC}$, not all cases were antimitochondrial antibody-positive ( $18 \%$ negative). There was a family history of PBC confirmed by medical records in $33 \%$ of cases. There were five multiplex families identified, one with seven affected individuals. Detailed family histories revealed a recurrence risk of $4 \%$ for PBC for all first-degree relatives older than 21 years of age, but $10 \%$ when considering only women. Other autoimmune conditions coexisted in PBC patients in 79\% of all cases. Arthritis was most frequent (60\%), with thyroid disease (16\%) and systemic lupus erythematosus (12\%) also present. Additionally, a history of autoimmune diseases (arthritis, systemic lupus erythematosus and thyroid disease) was present in $21 \%$ of first-degree relatives. A strong genetic predisposition to $\mathrm{PBC}$ and other autoimmune diseases, combined with common environmental factors, is postulated in this population. Further study is underway to identify these factors.

Key Words: American Indians; Autoimmune liver disease; First Nations; Genetic predisposition; Primary biliary cirrhosis; Recurrence risk

The progressive destruction of small intrahepatic bile 1 ducts is the hallmark of primary biliary cirrhosis (PBC), widely believed to have an autoimmune basis. Portal inflammation, progressive scarring and liver cirrhosis lead to liver failure and result in a median length of survival of seven to 16 years, depending on whether the condition is recognized

\section{Caractéristiques de la cirrhose biliaire primaire chez les Autochtones de la Colombie- Britannique}

La cirrhose biliaire primaire (CBP) est une rare maladie hépatique autoimmune caractérisée par une destruction progressive des canaux biliaires intrahépatiques qui entraîne une inflammation portale, la formation de tissu cicatriciel, la cirrhose et l'insuffisance hépatique. Bien que rare au sein de la population canadienne, elle est la première cause de demande de consultation pour transplantation hépatique chez les Autochtones de la Colombie-Britannique. Une revue élargie de tous les cas référés à la British Columbia Transplant Society pour CBP a été effectuée; on y comparait les caractéristiques démographiques des individus selon qu'ils étaient ou non d'origine autochtone. Selon cette revue, le taux de demande de consultation pour transplantation était huit fois plus grand chez les individus d'origine autochtone $(\mathrm{P}=0,0001)$ et un nombre disproportionné de ces cas vivait sur l'île de Vancouver (48\% des cas, contre $18 \%$ selon les prévisions, $\mathrm{P}<0,05)$. De plus, l'âge des sujets d'origine autochtone au moment de la demande de consultation était beaucoup plus bas ( 45,9 ans, vs 54,3 ans) et on a noté un nombre d'hommes d'origine autochtone moindre que prévu (1:34). Aux fins du présent rapport, 28 cas symptomatiques ont été confirmés séparément et passés en revue dans le cadre d'une étude clinique pour déterminer les caractéristiques de cette population.

RÉSULTATS : Les rapports de biopsie hépatique disponibles concordaient avec un diagnostic de CBP, mais les cas n'étaient pas tous positifs à l'égard des anticorps antimitochondriaux (18 \% négatifs). On a confirmé la présence d'antécédents familiaux de CBP à l'examen des dossiers de $33 \%$ des sujets. Cinq familles multiplexes ont été identifiées, l'une regroupant sept sujets atteints. L'examen plus approfondi des histoires familiales a révélé un risque de récurrence de CBP de $4 \%$ chez tous les parents proches de plus de 21 ans, mais $10 \%$ ne tenaient compte que des femmes. Dans 79 \% de tous les cas de CBP, d'autres maladies autoimmunes coexistaient. L'arthrite arrivait au premier rang, avec une proportion de $60 \%$, suivi de la maladie thyroïdienne (16\%) et du lupus érythémateux disséminé (12\%). De plus, des antécédents de maladie auto-immune (arthrite, lupus, thyroïde) s'observaient chez $21 \%$ des parents proches. On avance l'hypothèse d'une forte prédisposition génétique à la CBP et à d'autres maladies auto-immunes, alliée à des facteurs environnementaux communs chez cette population. D'autres études se poursuivent pour identifier ces facteurs.

asymptomatically or symptomatically (1). Treatment with ursodeoxycholic acid (UDCA) has been found to reduce the likelihood of liver transplantation when used in a timely manner $(2,3)$. Consistent with other genetically complex traits, such as insulin-dependant diabetes mellitus, familial cases are reported to account for $1 \%$ to $5 \%$ of those affected, and

\footnotetext{
${ }^{1}$ Department of Genetics, University of British Columbia; ${ }^{2}$ British Columbia Transplant Society, Vancouver; ${ }^{3}$ Division of Medical Genetics, Department of Pathology, Victoria General Hospital, Victoria; ${ }^{4}$ Centre for Disease Control; ${ }^{5}$ Division of Gastroenterology, Department of Medicine, University of British Columbia, Vancouver, British Columbia

Correspondence and reprints: Dr Laura Arbour, University of British Columbia, Department of Medical Genetics, Room C234-4500 Oak Street, Vancouver, British Columbia V6H 3N1. Telephone 604-875-2827, fax 604-875-2376, e-mail larbour@cw.bc.ca
} 


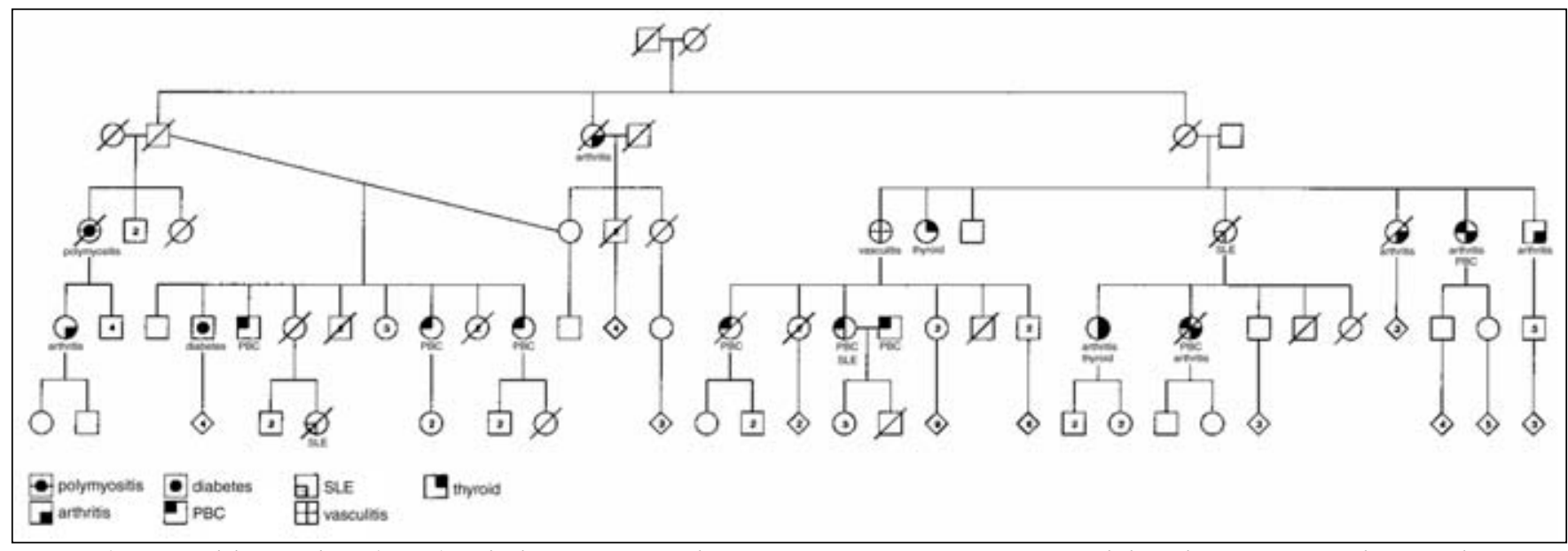

Figure 1) Primary biliary cirrhosis (PBC) and other autoimmune diseases in west coast First Nations extended family. SLE Systemic lupus erythematosus

these are generally limited to recurrences of two to three cases per kindred, most often mother-daughter pairs (4-6). Additionally, and consistent with other autoimmune diseases, PBC predominantly affects women, with the ratio of men to women averaging approximately $1: 10(7,8)$. Although familial rates of the condition in extended families are often referred to, few studies have effectively calculated recurrence risks for first-degree relatives. However, when carried out properly, the recurrence risk in first-degree relatives is calculated to be less than $1 \%(9)$. Considered by some to be a model complex genetic disease, attempts to delineate the genetic basis of PBC have proven to be largely unsuccessful, as is the case with any rare condition with a paucity of large affected kindreds $(9,10)$. However, associated studies have yielded varying positive results with some human leukocyte antigen (HLA) alleles, tumour necrosis factor alpha, cytotoxic T lymphocyte antigen-4, vitamin $\mathrm{D}$ receptor polymorphisms and specific mannosebinding lectin (11-14). One apolipoprotein E allele may confer less responsiveness to UDCA therapy and may partly explain an increased vulnerability to rapid progression of the disease (15).

$\mathrm{PBC}$ is associated with other autoimmune disorders, including scleroderma, rheumatoid arthritis, Sjogren's syndrome, polymyositis, vasculitis and hypothyroidism (1). Although several immunological markers have been documented to be associated with PBC (antinuclear antibodies, antithyroid antibodies, lymphocytotoxic antibodies, antiacetylcholine receptor antibodies, antihistone antibodies and anticentromere antibodies) (1), antimitochondrial antibodies (AMA) are the most specific and are present in approximately $90 \%$ of those with the disorder (6). Although not a strong determining factor for the condition, HLA class II antigens may play a role in susceptibility in some populations. For example, DRB1*0803, 0801 and DPB1*0501 have been shown to have significantly higher frequencies in some populations affected with PBC (16).

The possibility of infectious agents contributing to the pathogenesis of PBC has stimulated considerable interest for some investigators (17). Of possible relevance to this is the isolation of human betaretrovirus from the biliary tissue of those affected with PBC (18). Furthermore, the suggestion that hepatitis $\mathrm{C}$ virus may induce both type II diabetes and autoimmune liver disease (19-21) is of potential interest in this population. Thus, the complexity of this 'complex disease' is demonstrated by the presence of one or more genetic factors combined with environmental exposure to key infectious agents that may substantially increase the risk of PBC in specific populations that live in geographical proximity to each other.

The high prevalence of PBC in British Columbia's First Nations people became apparent with a cluster of cases on Vancouver Island, including an extended family with seven cases in three sibships, all related through common great grandparents (Figure 1). Subsequently, it came to light that over a 10 -year period, $25 \%$ of those referred for transplant for PBC were of First Nations descent, thus showing that in British Columbia, where First Nations people represent approximately $4 \%(171,000)$ of the 3.9 million population (22), PBC is the leading cause of liver transplant referral (23). Furthermore, on expanded analysis of the British Columbia transplantation database (24), of 128 patients referred for liver transplantation for PBC, 34 of these were of First Nations descent (one in three) (OR 8.3, CI 5.6 to $12.21, \chi^{2} \mathrm{P}=0.0001$ ). Therefore, based on the size of the respective populations, First Nations people were referred eight times more frequently for PBC than those of other descent (24). The specific First Nation of origin was not available through the British Columbia transplant society data.

Also of interest are the residential demographics of PBC patients in British Columbia. Vancouver Island is a large island off the coast of British Columbia, containing approximately $17 \%$ of the province's population, including $18 \%$ of the province's First Nations population. A disproportionate number of First Nations people with PBC (48\% of patients referred for assessment of transplantation) live on Vancouver Island (24), a disproportion significant by Fishers exact test $(\mathrm{P}=0.02)$. Of the non-First Nations population, approximately $19 \%$ of patients were found on Vancouver Island (not significant).

Additionally, the British Columbia transplant society data analysis demonstrated that for non-First Nations people, the ratio of men to women was 1:6; compared with the First Nations population where one in 34 patients were men (24). By Fishers exact test, these differences did not reach statistical significance $(\mathrm{P}=0.07)$. In addition, the average age for referral of the 34 First Nations patients on the British Columbia transplant list was 45.9 (range 32 to 59) years of age, compared with 54.3 (range 29 to 72 ) years of age for the 94 patients not of First Nations descent $(\mathrm{P}<0.001)$.

The above previously published analysis demonstrates that in British Columbia, the referral rate for $\mathrm{PBC}$ is eight times 
higher for First Nations people over that of non-First Nations people (24). Although the reason is unclear (whether fewer men are affected or fewer men are referred), men are referred for transplantation less often than non-First Nations individuals relative to the number of female patients. Finally, those of First Nations descent with PBC are more likely to live on Vancouver Island than those of other descent with PBC (24). Also interesting, was that the age of referral for transplantation was significantly lower for the First Nations patients, suggesting a more severe variant of the condition. Thus, with the database analysis as a background, the present study aimed to define the specific clinical and familial features present in this population.

\section{METHODS}

Patients of First Nations descent with PBC were ascertained by public announcement (First Nations Chiefs' Health Committee newsletter, British Columbia's First Nations newspaper) and through internists and primary care physicians' offices. The study was presented to and supported through the First Nations Chiefs' Health Committee of British Columbia.

To be included as a case, by convention, at least two out of the three main diagnostic criteria had to be fulfilled. Specifically, a positive liver biopsy, positive AMA and elevated liver enzymes characteristic of cholestatic damage (alkaline phosphatase or gamma-glutamyltransferase). Medical records were reviewed for the natural history of the condition and laboratory results, including the presence of immunogenetic markers and viruses. Biopsy records were obtained and reviewed, and First Nation of origin was documented in patients and their parents. Questionnaires were administered to determine demographics, coexisting morbidity and subjective symptomology.

Three-generation family histories were taken from all patients with attention to the presence of other autoimmune diseases. Segregation analysis was carried out to determine recurrence risks for first-degree relatives. Extended family history segregation analysis (second- to fourth-degree relative recurrence) was attempted but unsuccessful because of incomplete data in approximately one-third of all families.

\section{RESULTS}

Twenty-eight First Nations patients were enrolled in the clinical study (27 women and one man; 18 different families). All patients were reported to be affected with $\mathrm{PBC}$ by their treating physicians. Sufficient records confirming the above PBC diagnostic criteria were obtained in 24 patients. Some laboratory records were not available because they were considered obsolete or had been discarded in accordance with British Columbia's guidelines on maintenance of medical records. Twenty-four patients with complete records and family histories were reviewed.

The average age of PBC diagnosis was $42 \pm 9$ years of age, with a range of 22 to 59 years of age. A minority of patients had been followed for 'alcoholic cirrhosis' for several years before the diagnosis of PBC. The average age of entry into the present study was $52 \pm 8$ years of age, with a range 39 to 67 years of age.

Liver biopsy results were available for review in 22 patients. In one mildly symptomatic patient with a positive AMA titre (1:640), a liver biopsy had not been performed. In one other patient with a strongly positive AMA $(1: 1280)$, the biopsy had been performed 20 years ago and was consistent with PBC, but no longer available. Histology studies on all cases revealed features consistent with the diagnosis of PBC, with descriptors such as "inflammation and fibrosis of portal tracts with ductopenia", "uniform cirrhosis with lymphocytic inflammation in portal tracts, consistent with end stage PBC" and "typical of PBC, chronic inflammatory infiltrate of portal tracts".

Additionally, there were 22 AMA results available. Of these, four (18\%) were negative, but all had liver biopsies consistent with PBC. Moreover, there were at least three patients with negative AMA results at the onset of diagnosis; however, these patients eventually became positive during the course of their illness.

There were 23 tests performed to determine enzyme levels specific for cholestasis; all had an elevated presence of alkaline phosphatase or gamma-glutamyltransferase.

Serology results for hepatitis B were available for 24 patients, of which four were positive (two for hepatitis B surface antibody and two for hepatitis B surface antigen); one of these patients was also HIV positive. There were 20 serology results available for hepatitis $\mathrm{C}$, all of which were negative.

Clinical features were also evaluated. Pruritis (75\%), complaints of fatigue (45\%), dry eyes and mouth (50\%), upper quadrant pain (19\%) and Raynaud's phenomenon (16\%) were reported as features affecting quality of life in the 24 patients with confirmed diagnosis. Sixteen per cent of patients had undergone treatment for esophageal varices. Osteoporosis was not routinely screened for in the study population, but reported in $16 \%$ of patients. Six of $24(25 \%)$ patients had had liver transplants.

Additionally, coexisting autoimmune diseases in patients were examined. Excluding Sjogren's syndrome, 19 of 24 patients $(79 \%)$ reported at least one other autoimmune condition. Of 24 patients, $14(60 \%)$ had clinical features of arthritis, four $(16 \%)$ had thyroid involvement (three with hypothyroidism and one with Grave's disease) and three (12\%) had systemic lupus erythematosus (SLE).

Twenty-one per cent of first-degree relatives of probands reported autoimmune disease, most often arthritis, with thyroid disease and SLE also common. Of note, the mothers of two of the probands were diagnosed with SLE and polymyositis.

A family history of PBC was present in eight of 24 (33\%) patients with confirmed records. There were five multiplex families brought to attention. The most striking kindred had seven affected individuals in three sibships, all related through common great grandparents (Figures 1 to 4 ). A segregation analysis was carried out, calculated by tallying the number of affected first-degree relatives (excluding the proband), over the total number of first-degree relatives and, thus, determining the actual recurrence of PBC once it has occurred in a family. This was separately calculated for all, for those over 21 years of age, and for only women over 21 years of age; recurrence risks were $4 \%, 4 \%$ and $10 \%$, respectively. When excluding family 14 (see Figure 1), which may have a major gene affecting recurrence and, therefore, is less relevant to the other families, the recurrence risks for first-degree relatives were 3\%, $4 \%$ and $11 \%$, respectively. With the exception of two mother-daughter recurrences in the sample, these are all sibling recurrences. However, there are five other extended family recurrences in the study (second- to fourth-degree), where the denominator of the second- to fourth-degree relatives could not accurately be determined and, therefore, recurrence risks were not calculated.

Risk ratios $(\lambda)$ are used to measure genetic effect in complex traits. This ratio is reflective of the risk to relatives versus 


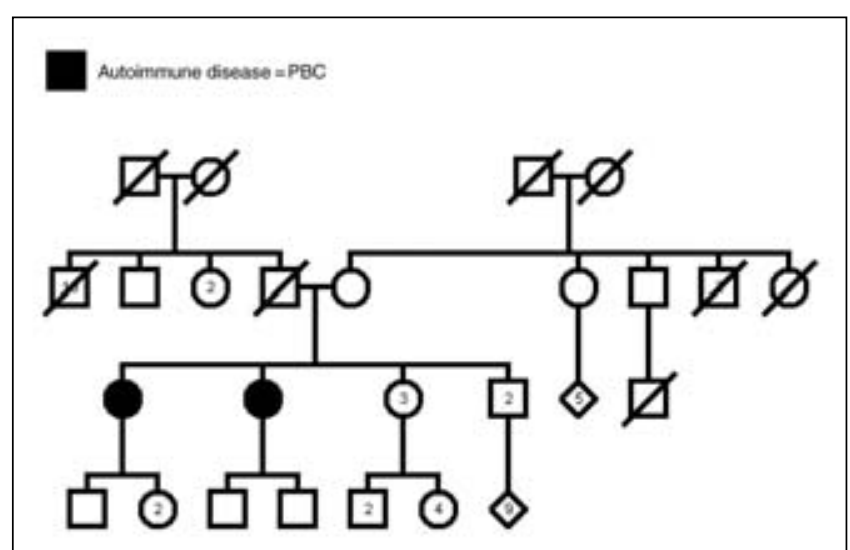

Figure 2) Examples of familial primary biliary cirrhosis (PBC) in the present study (filled circles designate afflicted females)

the population prevalence of a particular condition $\left(\lambda_{R}=k_{R} / k\right)$, where $\mathrm{k}$ is the population risk (25). Because any true prevalence data for $\mathrm{PBC}$ in British Columbia's population were unavailable, the present study compares two relevant populations where the prevalence had been previously determined. Thus, for the families in the present study, by using the population prevalence in Ontario ( 22 in 1,000,000), the $\lambda_{\mathrm{S}}$ (risk to siblings) was calculated to be 1500 . However, using a geographically closer and more recently calculated value, the estimate from Alaska (289 in 1,000,000) yields a $\lambda_{S}$ of 100 . Both ratios suggest a very strong genetic effect, with most autoimmune diseases reaching a $\lambda_{\text {S }}$ between 8 and 20 (10), with PBC consistent at a $\lambda_{\mathrm{S}}$ of 10.5 . For reference, an autosomal recessive trait such as cystic fibrosis has a $\lambda$ of 500 , Huntington's disease is 5000 and insulin-dependent diabetes is 15 (25).

Nation of origin was also reported. Sixty-three per cent (17 of 27) of patients were of either Nuu-chah-nulth, Coast Salish, Salish or Cowichan origin. With the exception of the Nuu-chah-nulth, they all arise from the Salishan coastal language and cultural group.

\section{DISCUSSION}

The presence of rheumatic disease (arthritis and SLE) is well documented in the First Nations people of British Columbia (26), Southeast Alaskan Indians (27) and other North American Native populations $(28,29)$. Excluding one report on Southeast Alaskan Indians (30), PBC has not been previously reported in North American Native peoples. Thus, it is of significance that $\mathrm{PBC}$ is the leading indication for liver transplantation in British Columbia's First Nations population, where based on population size, it is eight times more likely for a person of First Nations descent to be referred for liver transplant for PBC (24). Of relevance, the British Columbia Vital Statistics report (1991 to 1999) (31) suggests that deaths from chronic liver disease are five times higher in First Nations women than women of other descent (on Vancouver Island). The problem with this is that all deaths from chronic liver disease are tabulated as 'alcoholic related deaths' for public health purposes. In the case of First Nations women, these statistics may be misleading and may influence diagnostic practices and prevent timely treatment. Indeed, some of our patients were followed for several years with a diagnosis of 'alcoholic cirrhosis', until appropriate investigations were carried out. Of

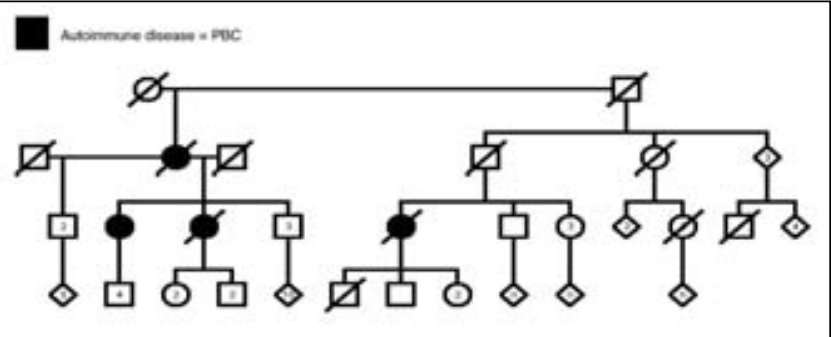

Figure 3) Examples of familial primary biliary cirrhosis (PBC) in the present study (filled circles designate afflicted females)

Autoimmune disease $=\mathrm{PBC}$

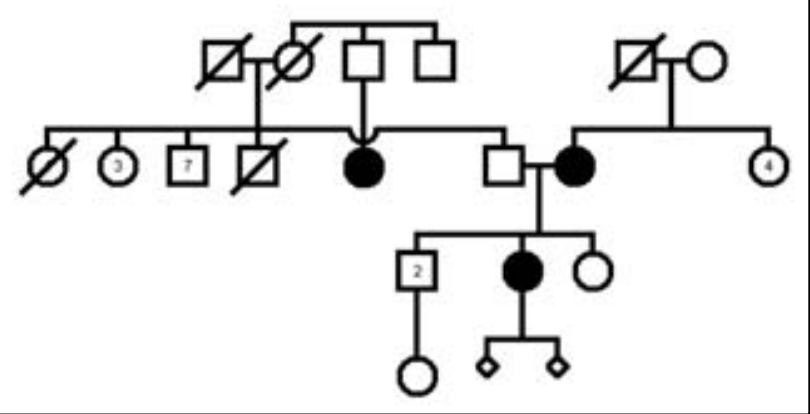

Figure 4) Examples of familial primary biliary cirrhosis (PBC) in the present study (filled circles designate afflicted females)

importance, once the diagnosis of $\mathrm{PBC}$ was made in the majority of our patients, alcohol use was stopped. Although, at this time, there is no evidence that alcohol consumption contributes to the pathology of $\mathrm{PBC}$, we cannot rule out a contribution to the progression rate in any given population. Because these data were not available in the database as a comparison between First Nations and non-First Nations patients, we could not assess this practical possibility. Further study would be necessary to investigate the affects of continued alcohol use on the natural history of PBC.

There was little evidence to suggest that the early onset of the condition was influenced by the coexistence of viral hepatitis. To date, no retroviral studies (such as human betaretrovirus or human T lymphotropic virus type 1) have been carried out. Only one patient was HIV-positive, suggesting that at least in this study population, HIV was not playing a role in the pathogenesis.

The clinical features of $\mathrm{PBC}$, including pruritis, fatigue, Raynaud's phenomenon, dry eyes and mouth, and right upper quadrant pain, were commonly reported in our study population, as in other populations $(1,32,33)$.

In our population, the rate of autoimmune disease (79\%) was similar to reports in the literature. However, the frequencies of specific autoimmune diseases differed, with the exception of thyroid disease which is usually present in approximately $20 \%$ of affected individuals (34). The leading autoimmune condition reported in the literature is keratoconjunctivitis sicca, apparent in $75 \%$ of patients (34). Dry eyes and mouth were reported in $50 \%$ of our patients; however, due to the vagueness of their symptoms, they were not specifically diagnosed with Sjogren's syndrome or keratoconjunctivitis sicca 
and they were therefore not included in our estimate of autoimmune disease. Significant, however, were the frequent reports of arthritis $(60 \%)$, which is present in approximately $20 \%$ of cases in the literature (34) and SLE, which our study reports more frequently in patients and family members than in the literature. This may reflect the higher incidence of arthritis and SLE in First Nations and American Indian populations reported both in the United States and Canada $(28,29)$. This association may be coincidental or may suggest a common predisposition to this pattern of autoimmune disease. Of special interest is the fact that southeast Alaskan Indians, who live in close geographical proximity to British Columbia and share a possible ancestral linkage, also have an increased incidence of SLE and arthritis (27). Thus, genes found to predispose to these conditions may be of importance in this population $(35,36)$.

The fact that four of 24 (18\%) patients had negative AMA and that at least three additional patients had negative AMA at the time of onset is interesting in our population. Although there may be variation in laboratory detection depending on the technique utilized, when properly analyzed AMA is said to be present in $95 \%$ of all patients (37). Some suggest that without a positive AMA, the more general term of autoimmune cholangitis should be used. Interestingly, several studies have demonstrated that these patients have a natural history of disease consistent with PBC, including their response to UDCA therapy (37). This is particularly of interest in our population, which may have similar origins to the southeast Alaskan population, who have an extremely high rate of combined AMA-positive and -negative PBC. Indeed, there is significant debate in the literature as to whether the presence of AMA contributes to the pathogenesis, or whether the presence is simply reflective of the condition (38). We suggest that in our population, a positive AMA may not be evident at the start of the disease process, thus giving more credibility to the suggestion that AMA is not itself the defining pathogenic initiator for PBC. Although, an autoimmune process is most likely in the patients and families of our population, we will not rule out the possibility that functional polymorphisms in genes for familial cholestasis (such as those found in North American and Greenlandic Native populations) are playing a role in the pathogenesis $(39,40)$.

The recurrence risk in our population for first-degree relatives is higher than seen in most populations (4\% to $10 \%$ ). Most studies report the prevalence of affected relatives, inflating the impression of recurrence risk. One study (41), initially reported the prevalence of affected relatives in their study to be eight in 157 (5\%). They went on to ascertain the number of first-degree relatives of patients (1118) and carrying out proper analysis, the sibling recurrence risk was then accurately reported to be $0.7 \%$. In the present study, although the medical records confirmed the prevalence of affected family members was 33\%, first-degree recurrence risk was lower but still significant enough to warrant closely monitoring first-degree relatives for features of the condition. Because so few published studies have calculated appropriate first-degree recurrence risks, it is difficult to compare whether our rates are more striking than others. However, this familial preponderance, as calculated with $\lambda_{\mathrm{S}}$ (of at least 100), suggests a strong genetic component and/or consistent environmental influence. Although sibling recurrence is the most common familial recurrence, suggesting both genetic and environmental influences, the presence of affected extended family members, presumably living in separate environments, is also supportive of a strong genetic component to the condition. On the other hand, in this population, the fact that one apparently unrelated male spouse of an affected individual in family 1 also recently developed PBC (Figure 1), suggests a strong environmental component to the condition.

Interestingly, two-thirds of our cases resulted from a common native coastal ancestry. As well, Hurlburt et al (30) noted that a combination of PBC and autoimmune cholangitis (defined as AMA-negative PBC) was most prevalent $(715$ in 1,000,000) in a population of Southeast Alaskan Indians; that population being similar geographically and possibly ancestrally to the British Columbia coastal Indians (Salishan ancestry). This further suggests the importance of genetic predisposition and, perhaps, the presence of a founder effect arising from Salishan ancestry, with admixture to the geographically close Nuu-chahnulth who live alongside the Cowichan and Salish. Further molecular genetic studies, including HLA haplotypes, may help to sort out these differences. Thus, we propose that one or more genetic factors, coupled with key environmental factors, are responsible for the excessively high rate of $\mathrm{PBC}$ in the First Nations population of British Columbia.

\section{CONCLUSIONS}

First Nations patients in British Columbia are much more likely to be referred for PBC than those of other descent. Additionally, the First Nations patients with PBC are more likely to be women, live on Vancouver Island and are referred at a younger age to be evaluated for liver transplantation. A specific pattern of rheumatoid disease, including arthritis and SLE, and hypothyroidism coexist in patients and relatives. The heritability $(\lambda)$ is greater than that reported in the literature for other autoimmune diseases, suggesting a strong genetic predisposition which may be influenced by common environmental factors.

Compared with other populations, the condition may represent a unique entity, a variation of classic PBC with a younger age of onset, a faster rate of progression and a less likely to be positive AMA. Because early treatment may mitigate the progression, women and men from British Columbia's First Nations population with symptoms of liver disease should be evaluated for PBC in addition to exploring for other more common causes. AMA is a simple and inexpensive test and should be carried out in all suspicious cases, especially in relatives of affected individuals. In some patients, if AMA is negative, a liver biopsy may be important in making the diagnosis.

Further research into the etiology and natural history of the condition in this population will serve to inform those involved in First Nations health care and the communities affected. Potentially, this will allow for a more timely diagnosis and treatment, which may mitigate the debilitating effects of the condition.

ACKNOWLEDGEMENTS: We are grateful to the families and community members who have participated in this study and given their time to improve education on the condition. As well, we are grateful to the many First Nations advisors who have contributed to the development of the project and have assisted in raising the awareness of the condition within their communities. This research has been supported in part by the Vancouver Foundation (BCM02-0015). As well, L Arbour is funded through the Canadian Institutes of Health Research Institute of Genetics, Clinical Investigatorship program. 


\section{REFERENCES}

1. Kaplan MM. Primary biliary cirrhosis. N Engl J Med 1996;335:1570-80.

2. Poupon RE, Bonnand AM, Chretien Y, Poupon R. Ten-year survival in ursodeoxycholic acid-treated patients with primary biliary cirrhosis. The UDCA-PBC Study Group. Hepatology 1999;29:1668-71.

3. Pares A, Caballeria L, Rodes J, et al. Long-term effects of ursodeoxycholic acid in primary biliary cirrhosis: Results of a double-blind controlled multicentric trial. UDCA-Cooperative Group from the Spanish Association for the Study of the Liver. J Hepatol 2000;32:561-6.

4. Brind AM, Bray GP, Portmann BC, Williams R. Prevalence and pattern of familial disease in primary biliary cirrhosis. Gut 1995;36:615-7.

5. Bach N, Schaffner F. Familial primary biliary cirrhosis. J Hepatol 1994;20:698-701

6. Caldwell SH, Leung PS, Spivey JR, et al. Antimitochondrial antibodies in kindreds of patients with primary biliary cirrhosis: Antimitochondrial antibodies are unique to clinical disease and are absent in asymptomatic family members. Hepatology 1992;16:899-905.

7. Borum ML. Hepatobiliary diseases in women. Med Clin North Am 1998;82:51-75.

8. Mayo MJ. Primary biliary cirrhosis: The future. Clin Liver Dis 2003;7:957-69.

9. Jones DE, Watt FE, Metcalf JV, Bassendine MF, James OF. Familial primary biliary cirrhosis reassessed: A geographically-based population study. J Hepatol 1999;30:402-7.

10. Gershwin ME, Leung PS, Li H, Seldin MF. Primary biliary cirrhosis and autoimmunity: Evaluating the genetic risk. Isr Med Assoc J 2000;2(Suppl):7-10

11. Gordon MA, Oppenheim E, Camp NJ, di Giovine FS, Duff GW, Gleeson D. Primary biliary cirrhosis shows association with genetic polymorphism of tumour necrosis factor alpha promoter region. J Hepatol 1999;31:242-7.

12. Agarwal K, Jones DE, Daly AK, et al. CTLA-4 gene polymorphism confers susceptibility to primary biliary cirrhosis. J Hepatol 2000;32:538-41.

13. Matsushita M, Miyakawa H, Tanaka A, et al. Single nucleotide polymorphisms of the mannose-binding lectin are associated with susceptibility to primary biliary cirrhosis. J Autoimmun 2001;17:251-7.

14. Vogel A, Strassburg CP, Manns MP. Genetic association of vitamin $\mathrm{D}$ receptor polymorphisms with primary biliary cirrhosis and autoimmune hepatitis. Hepatology 2002;35:126-31.

15. Corpechot C, Benlian P, Barbu V, Chazouilleres O, Poupon RE, Poupon R. Apolipoprotein E polymorphism, a marker of disease severity in primary biliary cirrhosis? J Hepatol 2001;35:324-8.

16. Jones DE, Donaldson PT. Genetic factors in the pathogenesis of primary biliary cirrhosis. Clin Liver Dis 2003;7:841-64.

17. Wadstrom T, Ljungh A, Willen R. Primary biliary cirrhosis and primary sclerosing cholangitis are of infectious origin! Gut 2001;49:454.

18. Xu L, Shen Z, Guo L, et al. Does a betaretrovirus infection trigger primary biliary cirrhosis? Proc Natl Acad Sci 2003;100:8454-9.

19. Mason A. Viral induction of type 2 diabetes and autoimmune liver disease. J Nutr 2001;131:2805S-2808S.

20. Martin JD, Yidegiligne HM. Diabetes mellitus in the First Nations population of British Columbia. Int J Circumpolar Health 1998;57(Suppl 1):335-9.

21. Hill W, Mak S, Descantes C, Engwer L, Krajden M. Geographic Information Systems (GIS) for policy development and planning of hepatitis $\mathrm{C}(\mathrm{HCV})$ virus prevention and care in British Columbia:
Frontiers in Viral Hepatitis,” Kapalua, Maui, Hawaii, Dec 16-20, 2001. (Abst)

22. Statistics Canada 2001 census profile. <http://www.bcstats.gov.bc.ca/data/cen01/profiles/59000000.pdf>. (Version current at April 5, 2005).

23. Yoshida EM, Caron NR, Buczkowski AK, et al. Indications for liver transplantation in British Columbia's Aboriginal population: A ten year retrospective analysis. Can J Gastroenterol 2000;14:775-9.

24. Arbour L, Field L, Ross P, Erikson A, Yoshida E. The mystery of primary biliary cirrhosis in British Columbia's First Nations people. Int J Circumpolar Health 2004;63(Suppl 2):185-8.

25. Farrer LA, Cupples LA. Determining the genetic component of a disease. In: Haines J, Pericak-Vance MA, eds. Approaches to Gene Mapping in Complex Human Diseases. New York: Wiley-Liss, 1998:93-130.

26. Atkins C, Reuffel L, Roddy J, Platts M, Robinson H, Ward R. Rheumatic disease in the Nuu-Chah-Nulth native Indians of the Pacific Northwest. J Rheumatol 1988;15:684-90.

27. Boyer GS, Templin DW, Lanier AP. Rheumatic diseases in Alaskan Indians of the southeast coast: High prevalence of rheumatoid arthritis and systemic lupus erythematosus. J Rheumatol 1991;18:1477-84.

28. Peschken CA, Esdaile JM. Systemic lupus erythematosus in North American Indians: A population based study. J Rheumatol 2000;27:1884-91

29. Peschken CA, Esdaile JM. Rheumatic diseases in North America's indigenous peoples. Semin Arthritis Rheum 1999;28:368-91.

30. Hurlburt KJ, McMahon BJ, Deubner H, Hsu-Trawinski B, Williams JL, Kowdley KV. Prevalence of autoimmune liver disease in Alaska Natives. Am J Gastroenterol 2002;97:2402-7.

31. British Columbia Vital Statistics Agency. Regional analysis of health statistics for status Indians in British Columbia, 1992-2002. <http://www.vs.gov.bc.ca/stats/indian/index.html> (Version current at April 11, 2005).

32. Heathcote J. The clinical expression of primary biliary cirrhosis Semin Liver Dis 1997;17:23-33.

33. Laurin JM, DeSotel CK, Jorgensen RA, Dickson ER, Lindor KD. The natural history of abdominal pain associated with primary biliary cirrhosis. Am J Gastroenterol 1994;89:1840-3.

34. Talwalkar JA, Lindor KD. Primary biliary cirrhosis. Lancet 2003;362:53-61.

35. Tokuhiro S, Yamada R, Chang X, et al. An intronic SNP in a RUNX1 binding site of SLC22A4, encoding an organic cation transporter, is associated with rheumatoid arthritis. Nat Genet 2003;35:341-8.

36. Prokunina, Castillejo-Lopez C, Oberg F, et al. A regulatory polymorphism in PDCD1 is associated with susceptibility to systemic lupus erythematosus in humans. Nat Genet 2002;32:666-9.

37. Poupon R. Autoimmune overlapping syndromes. Clin Liver Dis 2003;7:865-78

38. Leung PS, Coppel RL, Ansari A, Munoz S, Gershwin ME. Antimitochondrial antibodies in primary biliary cirrhosis. Semin Liver Dis 1997;17:61-9.

39. Chagnon P, Michaud J, Mitchell G, et al. A missense mutation (R565W) in cirhin (FLJ14728) in North America Indian childhood cirrhosis. Am J Hum Genet 2002;71:1443-9.

40. Klomp LW, Bull LN, Knisely AS, et al. A missense mutation in FICI is associated with greenland familial cholestasis. Hepatology 2000;32:1337-41.

41. Jones DE, Watt FE, Metcalf JV, Bassendine MF, James OF. Familial primary biliary cirrhosis reassessed: A geographically based population study. J Hepatol 1999;30:402-407. 


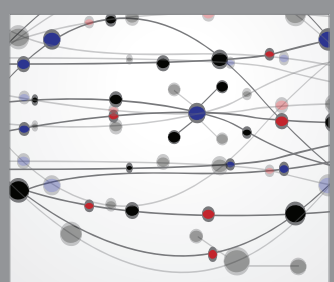

The Scientific World Journal
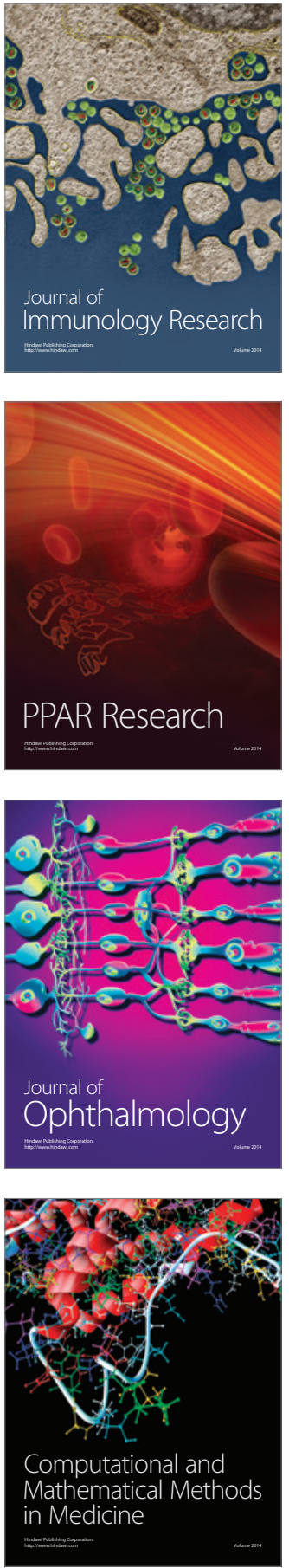

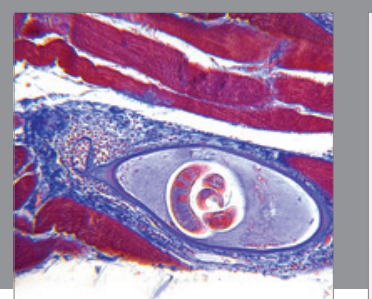

Gastroenterology Research and Practice

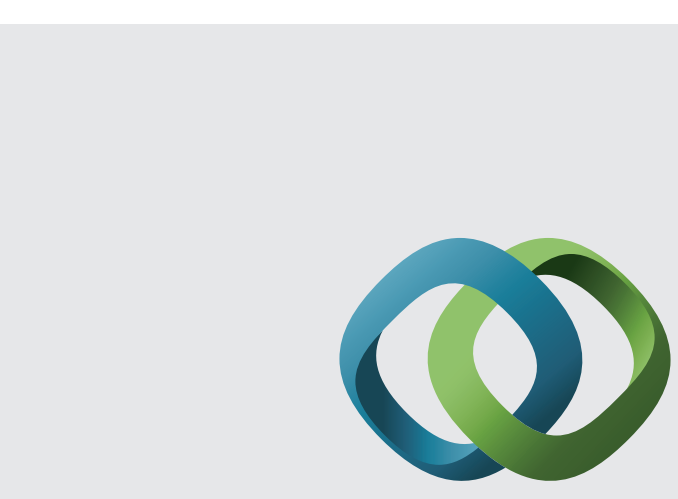

\section{Hindawi}

Submit your manuscripts at

http://www.hindawi.com
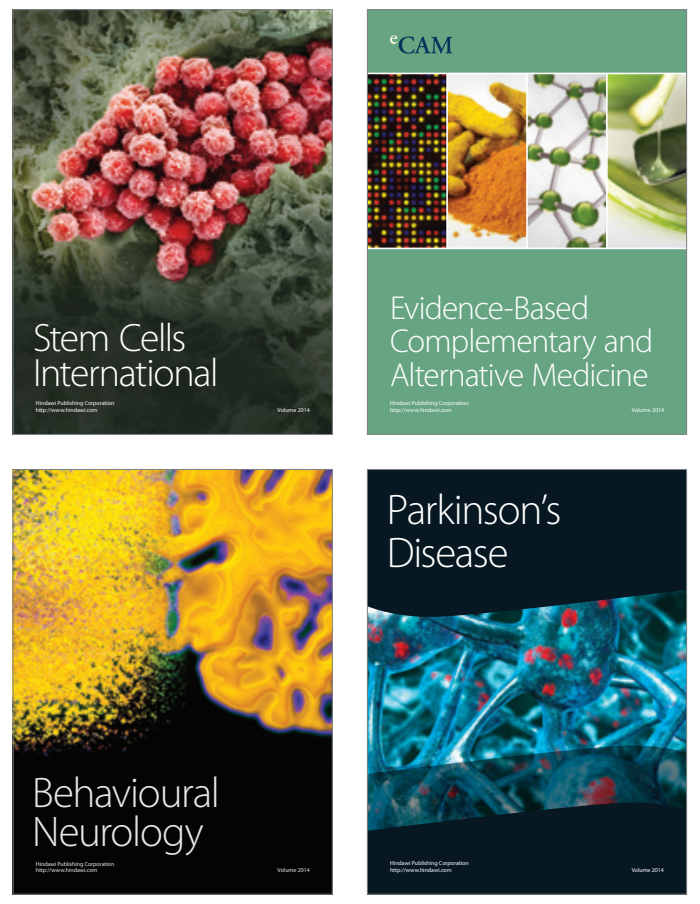
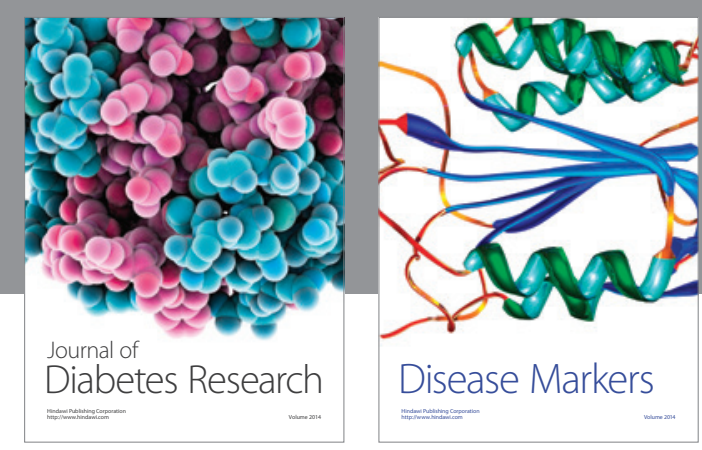

Disease Markers
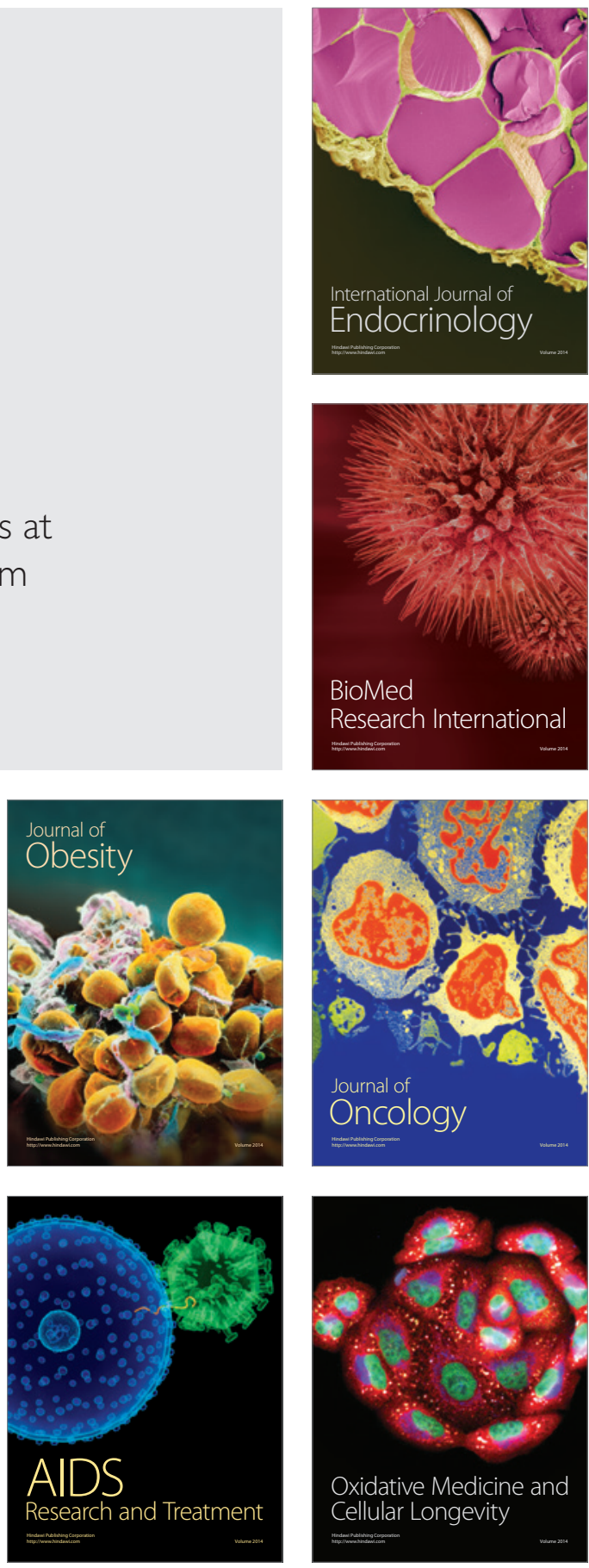